\title{
Advanced Electron Microscopy Characterisation of Important Precipitation and Ordering Phenomena in Shape Memory Systems
}

\author{
Dominique Schryvers ${ }^{1}$
}

Published online: 21 April 2015

(C) ASM International 2015

\begin{abstract}
The present paper discusses some important aspects of precipitation and ordering in alloy systems that show a martensitic transformation and can or are used as shape memory or superelastic metallic systems. The precipitates are investigated by a variety of conventional and advanced electron microscopy techniques, including atomic resolution, 3D slice-and-view, energy loss spectroscopy etc. Depending on the system, such secondary phases can decrease the probability of a displacive transformation by changing the phase stability in the system, such as in the case of $\mathrm{Ni}-\mathrm{Al}$ or Ni-Ti-Pd, or can mechanically hinder the passage of the transformation interface, as in $\mathrm{Ni}-\mathrm{Ti}-\mathrm{Nb}$. On the other hand, properly controlling the nucleation and growth of some precipitates can strongly improve the properties of some types of materials, as is the case for the well-known $\mathrm{Ni}_{4} \mathrm{Ti}_{3}$ precipitates.
\end{abstract}

Keywords Precipitation - Ordering - TEM - SEM · $\mathrm{Ni}-\mathrm{Al} \cdot \mathrm{Ni}-\mathrm{Ti}$

\section{Introduction}

The appearance of shape memory (SM) and superelasticity (SE) behaviour in selected alloys is based on the diffusionless and reversible martensitic phase transformation. According to the classification scheme first presented by Cohen et al. [1], this type of transformation implies a

Dominique Schryvers

nick.schryvers@uantwerpen.be

1 EMAT, University of Antwerp, Groenenborgerlaan 171, 2020 Antwerp, Belgium homogeneous lattice-distortive strain (as apposed to shuffle movements), which transforms one Bravais lattice into another one. Moreover, the strain needs to be shear dominated (as opposed to dominated by dilatations) so that an undistorted line exists between the parent and product phase. For a genuine martensitic transformation, the kinetics and morphology also need to be dominated by the strain energy (as opposed to being due to atom vibrational displacements). Typical examples of alloys accommodating this type of transformation are low-carbon steel, some $\mathrm{Cu}$-based alloys and $\mathrm{Ni}-\mathrm{Ti}$-based systems (although many other systems exist as well). However, for alloys to perform properly in the functional circumstances of shape memory and superelasticity as required by the conditions of a particular application, the system needs to be trained under well-defined thermal and mechanical conditions. As a result of this training (and especially its thermal component), the micro- and sometimes also the nanostructure of the alloy can become very complex, often including the precipitation of (meta)stable secondary phases in the form of precipitates, ordered structures etc. Without these particular structural features, the requested shape memory and superelastic behaviour would often not occur (or at least not to the satisfaction of the user), but since they are also often more stable than the metastable martensite phase, they can overrule the displacive martensitic transformation so the competition and interactions between the different structures need to be understood very well.

In the present paper, the focus will be on the use of advanced scanning and transmission electron microscopy (S/TEM) techniques used for the characterisation of such micro- and nanostructures. For a first example we return to conventional high-resolution TEM (HRTEM) and to the $\mathrm{Ni}-\mathrm{Al}$ system, an alloy was heavily investigated in the second half of the previous century to understand the 
physical properties and driving forces of the (pre-)martensitic transformation. In the second example, various more advanced S/TEM examples aiming for better quantification of the all important but metastable $\mathrm{Ni}_{4} \mathrm{Ti}_{3}$ precipitates in near-equiatomic $\mathrm{Ni}-\mathrm{Ti}$ will be discussed. For some last examples, we focus on precipitates occurring in ternary Ni-Ti-based systems, such as Ni-Ti-Pd and Ni$\mathrm{Ti}-\mathrm{Nb}$. For technical details on the sample preparation and used microscopy techniques, we refer to the respective papers.

\section{Results and Discussion}

\section{$\mathrm{Ni}_{5} \mathrm{Al}_{3}$ in $\mathrm{Ni}-\mathrm{Al}$}

For a long time, the Ni-rich part of the $\mathrm{Ni}-\mathrm{Al}$ system, i.e. between 62 and 66 at.\% $\mathrm{Ni}$, was considered as a potential candidate for high-temperature SM behaviour since the transformation temperatures, although strongly depending on concentration, can go up to several hundreds of centigrades [2]. However, as is clear from the phase diagram originally published by Bradley and Taylor [3] and later refined by several others (see, e.g. [4]), when treating or operating the material at elevated temperatures up to $700{ }^{\circ} \mathrm{C}$, the stable $\mathrm{Ni}_{5} \mathrm{Al}_{3}$ structure nucleates in the austenite B2 matrix and this new structure does not transform to martensite so no SM behaviour exists anymore. In fact, the basic lattice of this orthorhombic $\mathrm{Ni}_{5} \mathrm{Al}_{3}$ structure strongly resembles that of the tetragonal $\mathrm{L}_{0}$ martensite, the main difference being the accompanying diffusional component yielding a unit cell four times as large by doubling the shortest and one of the longest axes of the martensite cell and yielding twice as many variants [5, 6]. As a result, the nucleation of this structure is also accompanied by the formation of so-called self-accommodating structures in which the internal strain is minimised by the combination of several variants. In Fig. 1 an example of such a configuration is shown as observed at low magnification HRTEM in a $\mathrm{Ni}_{62.5} \mathrm{Al}_{27.5}$ sample annealed for $2 \mathrm{~h}$ at $550{ }^{\circ} \mathrm{C}$ and in which all three possible deformation variants are combined in two by two wings extending from a central nucleation point [5]. Despite the highly symmetric shape combining different variants and seen when observing the surrounding matrix along a $\langle 111\rangle_{\mathrm{B} 2}$ direction, the accommodation is not perfect and the matrix-precipitate interfaces contain equidistant interfacial dislocations to accommodate the remaining interfacial lattice mismatch between the two structures. Assuming the $\mathrm{Ni}_{5} \mathrm{Al}_{3}$ structure has its expected stoichiometric concentration, which equals the nominal composition of the $\mathrm{Ni}_{62.5} \mathrm{Al}_{27.5}$ alloy, the nucleation and growth of these precipitates are only accompanied with local short range atom diffusion

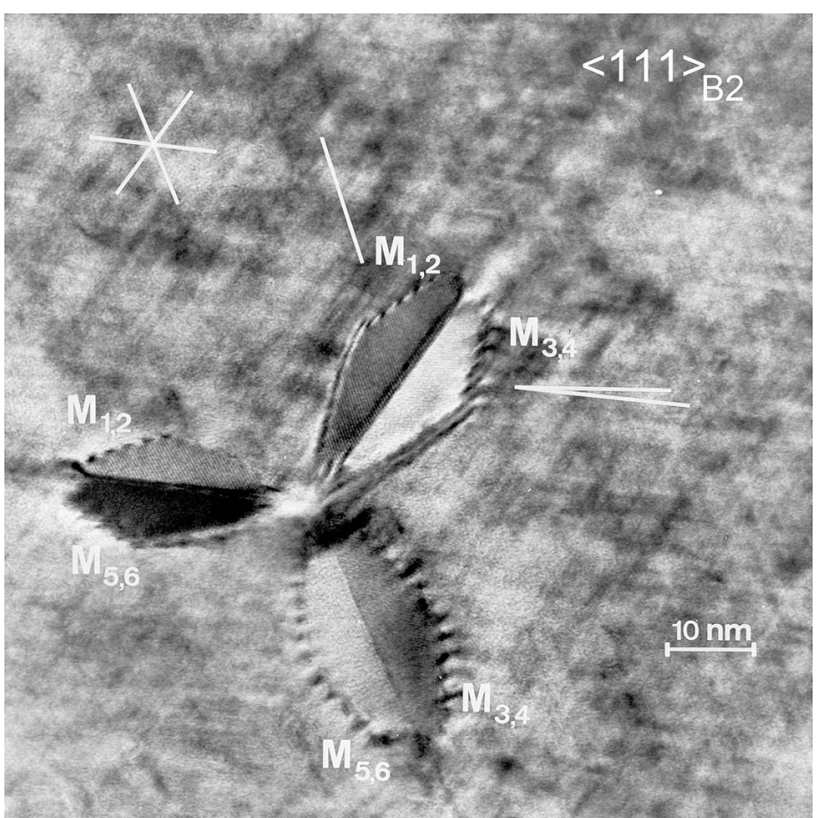

Fig. $1\langle 111\rangle_{\mathrm{B} 2}$ low magnification HRTEM image of a star-shaped $\mathrm{Ni}_{5} \mathrm{Al}_{3}$ precipitate in annealed $\mathrm{Ni}_{62.5} \mathrm{Al}_{27.5}$ and combining different variants to minimise deformation strains. Still, interface dislocations are seen between the precipitate and matrix. (the indices refer to the two possibilities of ordering for each deformation variant) [6]

and will not influence the concentration of the surrounding matrix. As a result also the (low) transformation temperature and martensite $14 \mathrm{M}$ fine structure will be the same as for the original material [7]. Furthermore, according to the phase diagram, when continuing the annealing for longer times, the entire B2 austenite matrix will transform into this stable twinned $\mathrm{Ni}_{5} \mathrm{Al}_{3}$ structure and no martensitic transformation can be observed anymore. When annealing quenched material with slightly higher Ni concentrations, e.g. $\mathrm{Ni}_{65} \mathrm{Al}_{35}$, which is in the martensite state even at these elevated temperatures (e.g. $550{ }^{\circ} \mathrm{C}$ ), the martensite lattice reorders directly into the $\mathrm{Ni}_{5} \mathrm{Al}_{3}$ structure, again stopping the possibility for any further displacive transformations [8]. In this particular system, the nucleation and growth of the ordered $\mathrm{Ni}_{5} \mathrm{Al}_{3}$ structure thus strongly hinder potential applications as SM or SE system, certainly at elevated temperatures.

\section{$\mathrm{Ni}_{4} \mathrm{Ti}_{3}$ in $\mathrm{Ni}-\mathrm{Ti}$}

In contrast to the disturbing effects of the nucleation and growth of the $\mathrm{Ni}_{5} \mathrm{Al}_{3}$ structure in $\mathrm{Ni}-\mathrm{Al}$, the $\mathrm{Ni}_{4} \mathrm{Ti}_{3}$ precipitates nucleating in near-equiatomic Ni-rich $\mathrm{Ni}-\mathrm{Ti}$ material are very important for the martensitic transformation and related SM and SE effects [9]. Although these precipitates are metastable and will thus disappear after prolonged annealing times, controlled thermo-mechanical treatments can create particular configurations of lenticular 
$\mathrm{Ni}_{4} \mathrm{Ti}_{3}$ precipitates in which the latter can act as nucleation sites of the transformation and support the SM behaviour at the microscopic level [10]. Moreover, due to the difference in concentration between the precipitates and the matrix and the resulting decrease of $\mathrm{Ni}$ in the latter upon precipitation, the annealing will stabilise the matrix concentration and thus the transformation temperatures, which are also in this system strongly dependent on composition [9, 11, 12].

Using the multislice least squares (MSLS) method, we first determined the exact atomic structure of well-developed $\mathrm{Ni}_{4} \mathrm{Ti}_{3}$ precipitates in $\mathrm{Ni}_{52} \mathrm{Ti}_{48}$ alloy solution treated at $950{ }^{\circ} \mathrm{C}$ for $30 \mathrm{~min}$ followed by water quenching and ageing for $4 \mathrm{~h}$ at $520^{\circ} \mathrm{C}$ [13]. In this method, electron diffraction intensities measured by a calibrated CCD are compared with simulated dynamical intensities calculated using the multislice method [14, 15]. By optimising the match between the experimental and calculated intensities, including the thickness and small misalignments as unknown parameters, site occupations and small atom shifts can be determined. As a result, the atomic positions of the $\mathrm{Ni}_{4} \mathrm{Ti}_{3}$ unit cell are refined, as shown in Fig. 2a, with no change in the R-3 symmetry of the earlier proposed unit cell [13]. The new unit cell also provides a better match between simulated and experimental high-resolution images, as seen in Fig. 2b. The observed atom shifts are found to be compatible with the lattice deformation by which the $\langle 111\rangle_{\mathrm{B} 2}$ direction is compressed and the lens shaped precipitates are formed on $\{111\}_{\mathrm{B} 2}$ planes.

As a result of the collapse of one set of $\{111\}_{\mathrm{B} 2}$ planes upon formation of the $\mathrm{Ni}_{4} \mathrm{Ti}_{3}$ precipitates, a strain field develops surrounding the precipitate. Since the martensitic transformation upon cooling can nucleate at these precipitates, often in the form of the intermediate R-phase [10, 16], this strain field is of vital importance for the SM and SE behaviour. From single-conventional high-resolution TEM (HRTEM) images of small precipitates produced in a $\mathrm{Ni}_{51} \mathrm{Ti}_{49}$ alloy subjected to a heat treatment of $1 \mathrm{~h}$ at $950{ }^{\circ} \mathrm{C}$ followed by water quenching and subsequently aged for $4 \mathrm{~h}$ at $450{ }^{\circ} \mathrm{C}$, the strain gradient in the surrounding matrix could be measured in 2D [17], while by combining two conventional HRTEM images obtained from different B2 zone axes, a 3D deformation matrix could be determined [18]. The symmetry and parameters of the latter correspond well with the transformation matrix of the R-phase, suggesting that this strain field indeed supports the R-phase nucleation at the precipitate-matrix interface. An example of a 2D strain map surrounding two nearby nanoprecipitates and obtained by geometric phase analysis (GPA) [19] from a HRTEM image is shown in Fig. 3a. At the same time, due to Ni enrichment in the precipitate, the surrounding matrix is depleted in Ni. This could be shown by spot-probe energy dispersive X-ray analysis (EDX) and electron energy loss spectroscopy
Fig. 2 a $\mathrm{Ni}_{4} \mathrm{Ti}_{3}$ unit cell as determined using MSLS optimisation and showing the atom shift when compared with the earlier model. b HRTEM images along two different zones including matching simulated insets. (the zones are defined in the rhombohedral (R) unit cell of the $\mathrm{Ni}_{4} \mathrm{Ti}_{3}$ structure) [13]

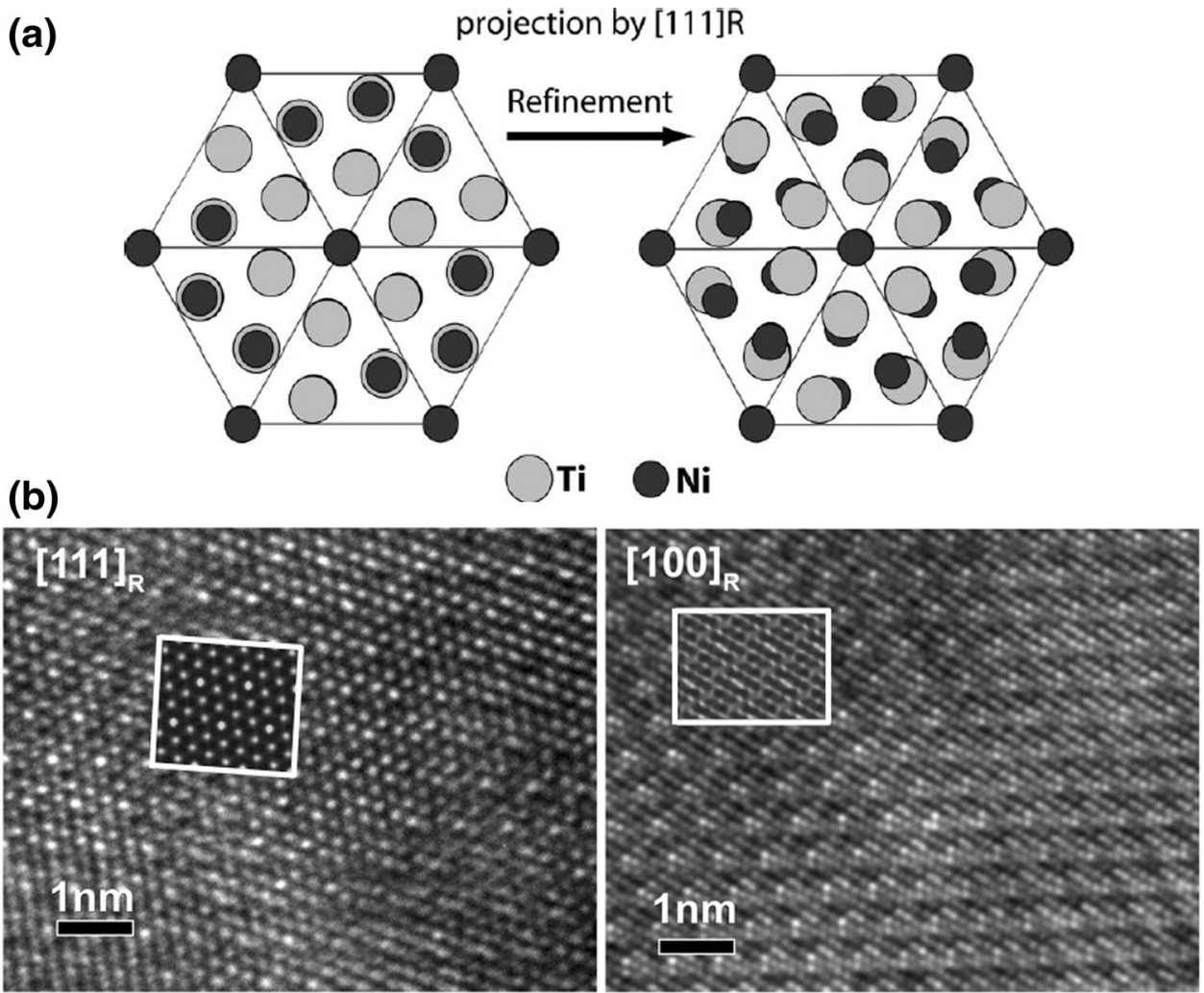


Fig. 3 a GPA map showing the strain gradients next to the long edges of $\mathrm{Ni}_{4} \mathrm{Ti}_{3}$

nanoprecipitates: the matrix is taken as a reference (green), the precipitates show a $1-2 \%$ compression (blue), while the strongest relaxation (1-3\%) occurs alongside the long edges of the precipitates (red to yellow). b EDX Ni-map of two crossing precipitates with an averaged trace revealing $\mathrm{Ni}$ depletion next to the precipitate. c EELS plasmon of the precipitate and austenite matrix $[20,22]$ (Color figure online)
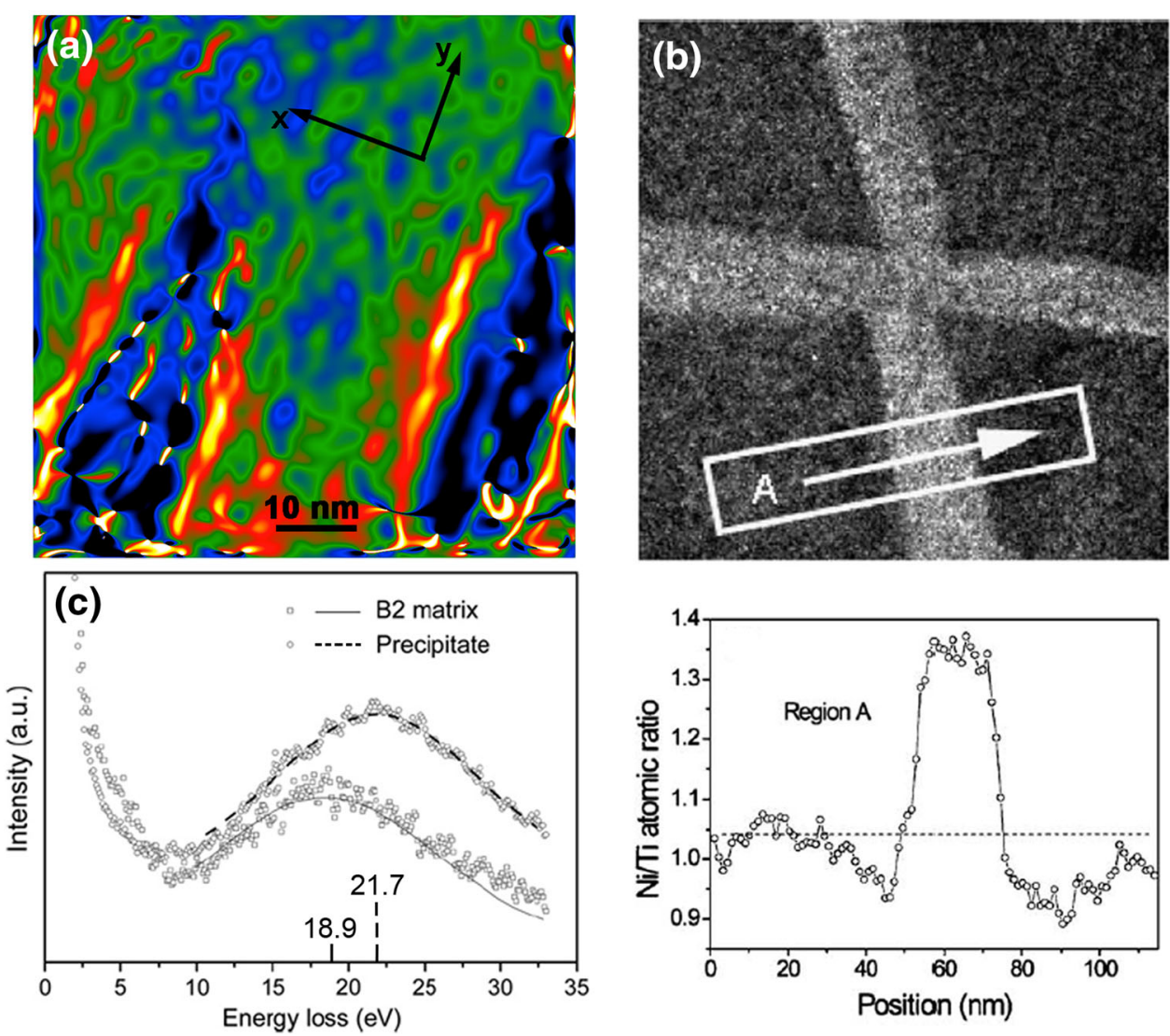

(EELS) measurements, again in solution treated $\mathrm{Ni}_{51} \mathrm{Ti}_{49}$ but now annealed for $4 \mathrm{~h}$ at $500{ }^{\circ} \mathrm{C}$, which revealed a small $\mathrm{Ni}$-depleted region next to the precipitate and of approximately the same dimension as the latter [20] (Fig. 3b). Lowering the $\mathrm{Ni}$ content can also trigger the martensitic transformation, but recent results attribute a stronger effect to the strain field [21].

EELS was also used on the same sample to determine the elastic moduli of the metastable $\mathrm{Ni}_{4} \mathrm{Ti}_{3}$ precipitates, by measuring the plasmon energy and comparing this with the value for the matrix as reference as shown in Fig. 3c [22]. As a result, it was concluded that the precipitates have a Young's modulus of $163 \pm 4 \mathrm{GPa}$, about $38 \%$ higher than that of the matrix, in other words, the precipitates are harder than the matrix explaining why they are not deformed during the martensitic transformation of the austenite.

Although these intrinsic properties of a single $\mathrm{Ni}_{4} \mathrm{Ti}_{3}$ precipitate embedded in austenite B2 matrix are very relevant for understanding the transformation behaviour at the atomic scale, the macroscopic SM and SE behaviour will be more affected by the actual overall configuration and organisation of the $\mathrm{Ni}_{4} \mathrm{Ti}_{3}$ precipitates. For example, in polycrystalline samples, the heterogeneity of the nucleation and growth of $\mathrm{Ni}_{4} \mathrm{Ti}_{3}$ precipitates have been found to yielding various kinds of multistep transformations due to the existence of different areas of precipitates with various sizes and density [23-26]. Close to the grain boundary of grains of several microns in diameter, many small precipitates exist, while the interior of the grains exhibits none or fewer but larger precipitates, resulting in different transformation paths and Ms temperatures in those different regions. In order to quantify these microstructures in three dimensions, 3D slice-and-view was performed in a FIB/SEM yielding clear numerical differences between the various regions. In Fig. $4 a$ the $3 \mathrm{D}$ configuration of the 4 families of micron-sized $\mathrm{Ni}_{4} \mathrm{Ti}_{3}$ precipitates observed in the centre of a large grain in a $\mathrm{Ni}_{50.8} \mathrm{Ti}_{49.2}$ alloy solution treated at $1000{ }^{\circ} \mathrm{C}$ for $1 \mathrm{~h}$, water quenched and annealed for $1 \mathrm{~h}$ at $550{ }^{\circ} \mathrm{C}$, is shown, while Fig. 4b shows the gradient from this region (right side) when moving closer to the grain boundary area (left side) with more but smaller precipitates [27, 28].

Moreover, when a material is annealed under stress, the $\mathrm{Ni}_{4} \mathrm{Ti}_{3}$ precipitates grow on preferential $111_{\mathrm{B} 2}$ planes so that ultimately only one family of precipitates will survive. In a single crystal sample of $\mathrm{Ni}_{51} \mathrm{Ti}_{49}$ annealed under $\langle 111\rangle_{\mathrm{B} 2}$ stress $\left(10 \mathrm{~h}, 550{ }^{\circ} \mathrm{C}, 50 \mathrm{MPa}\right)$, the $3 \mathrm{D}$ investigation revealed box-like stackings of parallel precipitates as seen in Fig. 4c [29]. As a result, the martensite plates are 


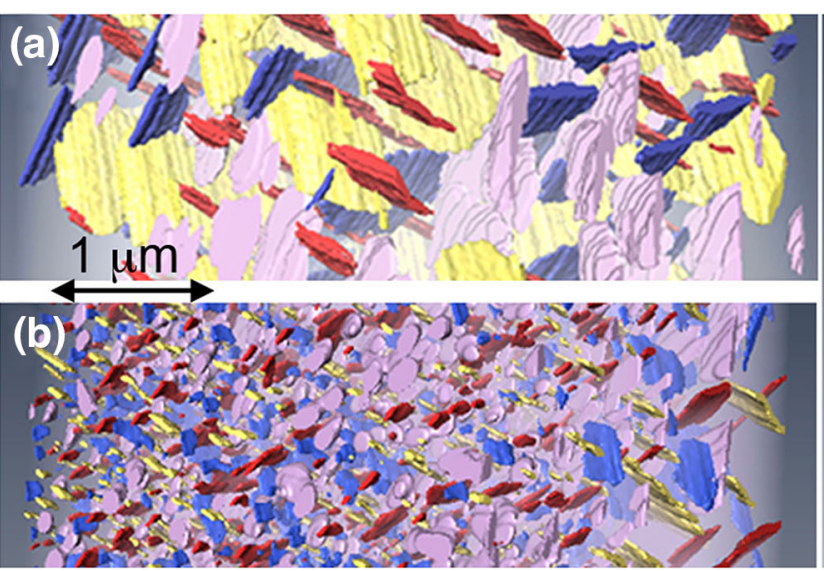

Fig. 4 3D configuration of $\mathrm{Ni}_{4} \mathrm{Ti}_{3}$ precipitates obtained by FIB/SEM slice-and-view in (a) the centre of a large grain and (b) closer towards the grain boundary (left). (c) The stacking of precipitates belonging to

strongly directed in between these parallel precipitates, although no long pathways exist, again affecting the macroscopic behaviour [16]. A similar phenomenon occurs in porous $\mathrm{Ni}_{50.8} \mathrm{Ti}_{49.2}$ material, aged for $6 \mathrm{~h}$ at $500{ }^{\circ} \mathrm{C}$, where the stress field surrounding micron-sized pores can induce directional preference in the growth of the $\mathrm{Ni}_{4} \mathrm{Ti}_{3}$ precipitates, as seen in Fig. 5 [30].

\section{Ni-Ti-X Ternary Systems}

When binary Ni-Ti is alloyed with a third element, particular combinations of precipitates can occur depending

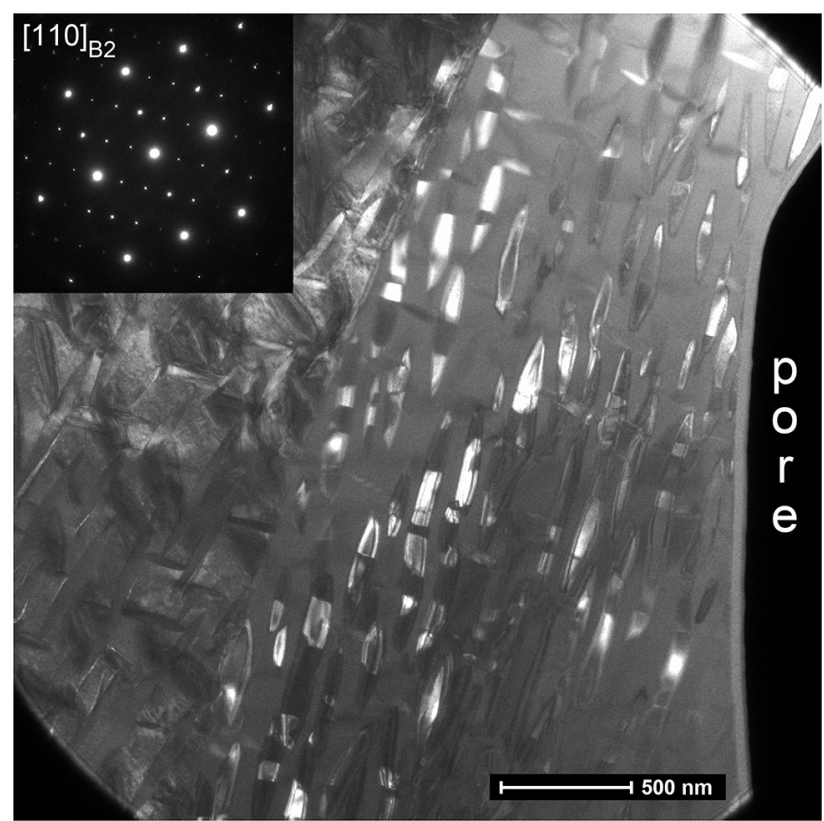

Fig. $5 \mathrm{Ni}_{4} \mathrm{Ti}_{3}$ precipitates grown next to a pore in annealed porous $\mathrm{Ni}_{50.8} \mathrm{Ti}_{49.2}$. In the grain at the edge of the pore, the precipitates are aligned and belong nearly all to the same family, as also seen from the diffraction inset, while in the next grain (left side) precipitates of all variants have comparable sizes

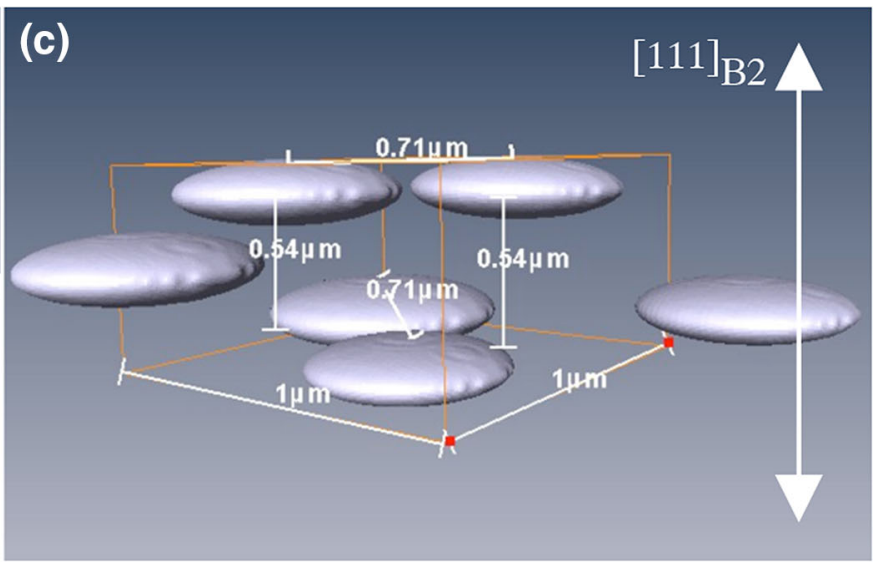

the same family as a result of annealing under stress along the indicated $[111]_{\mathrm{B} 2}$ direction $[27,29]$ (Color figure online)

on the solubility of the third element. For example, $\mathrm{Ni}_{30}$ $\mathrm{Ti}_{50} \mathrm{Pd}_{20}$ is investigated in the search for materials with low hysteresis and where the systematic replacement of $\mathrm{Ni}$ by Pd gradually changes the lattice parameters of the austenite and martensite so as to reach the $\lambda_{2}=1$ condition needed for minimal hysteresis [31]. In this system, several precipitation zones with different variants of tetragonal $\left(\mathrm{C}_{11 \mathrm{~b}}\right)$ $\mathrm{Ti}_{2} \mathrm{Pd}(\mathrm{Ni})$ platelets in the austenite $\mathrm{B} 2$ matrix surrounding a single ellipsoid $\mathrm{Ti}_{2} \mathrm{Ni}(\mathrm{Pd})$ particle exhibiting a cubic (Fd3m) structure were observed (Fig. 6) [32]. Outside of this precipitation zone, the material is in its martensite $\mathrm{B} 19$ phase. It is assumed that during the annealing at $800{ }^{\circ} \mathrm{C}$ for $5.5 \mathrm{~h}$ and the following quench to room temperature local

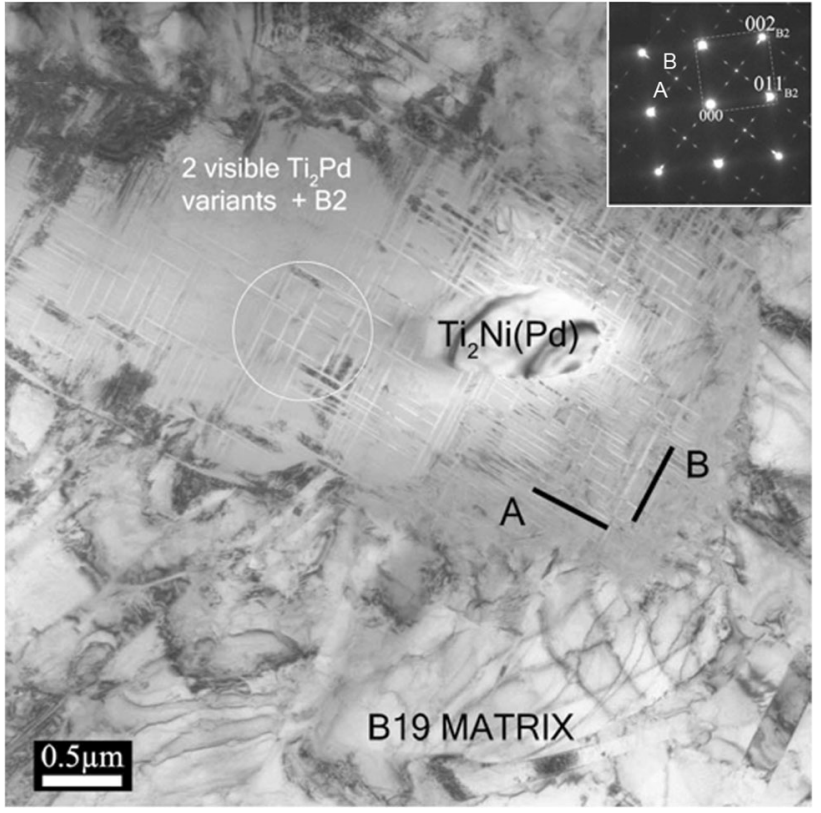

Fig. 6 Complex precipitation zone with different crystallographic variants of platelet $\mathrm{Ti}_{2} \mathrm{Pd}$ precipitates surrounding an ellipsoid $\mathrm{Ti}_{2} \mathrm{Ni}(\mathrm{Pd})$ particle in homogenised $\mathrm{Ni}_{30} \mathrm{Ti}_{50} \mathrm{Pd}_{20}$ [32] 

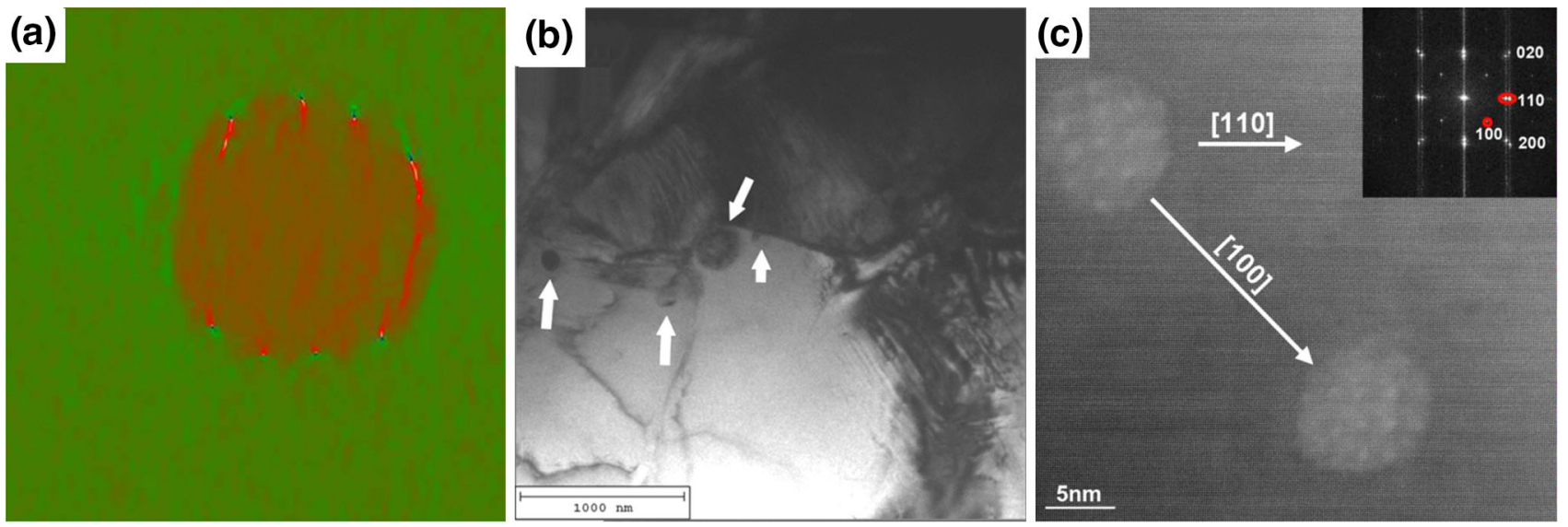

Fig. 7 a GPA of Nb-rich nano-sized precipitate in $\mathrm{Ni}-\mathrm{Ti}-\mathrm{Nb}$ revealing equidistant interface dislocations (as hotspots) accommodating the $10 \%$ lattice mismatch between precipitate and matrix.

fluctuations of the B2 matrix composition lead to the precipitation of $\mathrm{Ti}_{2} \mathrm{Ni}(\mathrm{Pd})$ particles accompanied by a precipitation of $\mathrm{Ti}_{2} \mathrm{Pd}(\mathrm{Ni})$ platelets in their immediate surroundings. Upon cooling, the $\mathrm{B} 2$ phase is retained in the immediate surroundings of the central $\mathrm{Ti}_{2} \mathrm{Ni}(\mathrm{Pd})$ precipitate since Ms is locally lowered due to a Pd depletion and/or a strengthening of the matrix by the coherent $\mathrm{Ti}_{2}$ $\operatorname{Pd}(\mathrm{Ni})$ precipitates. Obviously, such local fluctuations and precipitation not only influence the local transformation but also hamper the search for the delicate balance between composition and lattice parameters.

On the other hand, in the $\mathrm{Ni}-\mathrm{Ti}-\mathrm{Nb}$ system, the third element is added to increase the hysteresis. In this case, the $\mathrm{Nb}$ has very low solubility in the Ni-Ti matrix and a eutectic structure with Nb-rich particles is formed. Still, some $\mathrm{Nb}$ is retained in the matrix and depending on the cooling or annealing conditions this $\mathrm{Nb}$ further precipitates into nanoparticles. Although there is a large lattice misfit of $10 \%$ between the $\mathrm{Nb}$-rich precipitates and the $\mathrm{Ni}-\mathrm{Ti}$ matrix, both bcc-based structures, there is a one-to-one correlation between the respective lattice orientations with the lattice misfit being accommodated by interface dislocations every $10 / 11\{110\}$ lattice planes of the precipitate and matrix, resp., as seen in Fig. 7a. This accommodation is very efficient so that only very little remaining strain inside the B2 matrix is observed. Although several investigations indicate that the response of the soft $\mathrm{Nb}$-rich eutectic has the most pronounced effect on the transformation characteristics [33, 34], also these smaller precipitates can play an important role. Not only do they reduce the $\mathrm{Nb}$ content of the matrix, thus affecting the transformation temperatures via the concentration dependence [35], but they also hamper the movement of the transformation front as seen in the captured image of an in situ TEM annealing sequence where the b Austenite-martensite interface blocked by rows of nano-sized precipitates. c Two nanoprecipitates aligned along a cubic austenite direction $[35,36]$ (Color figure online)

austenite-martensite interface is seen to be halted by rows of precipitates formed in a commercial $(\mathrm{Ni}-\mathrm{Ti}) \mathrm{Nb}_{8.4}$ alloy extruded and quenched from $900{ }^{\circ} \mathrm{C}$ (Fig. 7b) [36]. The latter already nucleate as aligned nanoscale precipitates along cubic directions of the austenite matrix in homogenised and quenched samples as seen in Fig. 7c.

\section{Conclusions}

In conclusion it can be stated that the formation of secondary phases by short or long-range diffusion, often as nano-sized precipitates, can have a profound effect on the shape memory and superelastic potential of a material undergoing a martensitic transformation. Depending on the case at hand, such secondary phases can decrease the probability of a displacive transformation by changing the phase stability in the system or can mechanically hinder the passage of the transformation interface. On the other hand, properly controlling the nucleation and growth of some precipitates can strongly improve the properties of some types of materials.

Acknowledgments The author gratefully thanks all researchers involved in the S/TEM investigations of the above listed examples: Y. Ma (NiAl), W. Tirry, Z.Q. Yang, S. Cao (NiTi), R. Delville (NiTiPd), H. Shi, (NiTiNb). The Flemish Science Foundation as well as the European Commission are acknowledged for financial support on various projects.

\section{References}

1. Cohen M, Olson GD, Clapp PC (1979) On the classification of displacive phase transformations. In: Proceedings of international conference on martensitic transformations ICOMAT-79 pp 1-6 
2. Shapiro SM, Yang BX, Noda Y, Tanner LE, Schryvers D (1991) Neutron-scattering and electron-microscopy studies of the premartensitic phenomena in $\mathrm{Ni}_{x} \mathrm{Al}_{100-x}$ alloys. Phys Rev $\mathrm{B}$ 44:9301-9313

3. Bradley AJ, Taylor A (1937) An X-ray analysis of the nickelaluminium system. Proc R Soc Lond A 159:56-72

4. Okamoto H (2004) Al-Ni (Aluminum-Nickel). J Phase Equilib Diffus 25:394

5. Schryvers D, Ma Y, Toth L, Tanner L (1995) Electron microscopy study of the formation of $\mathrm{Ni}_{5} \mathrm{Al}_{3}$ in a $\mathrm{Ni}_{62.5} \mathrm{Al}_{37.5} \mathrm{~B} 2$ alloy I. Precipitation and growth. Acta Metall Mater 43:4045-4056

6. Schryvers D, Ma Y, Toth L, Tanner L (1995) Electron microscopy study of the formation of $\mathrm{Ni}_{5} \mathrm{Al}_{3}$ in a $\mathrm{Ni}_{62.5} \mathrm{Al}_{37.5} \mathrm{~B} 2$ alloy II. Plate crystallography. Acta Metall et Mater 43:4057-4065

7. Schryvers D (1993) Microtwin sequences in thermoelastic $\mathrm{Ni}_{x-}$ $\mathrm{Al}_{100-x}$ martensite studied by conventional and high-resolution transmission electron microscopy. Philos Mag A 68:1017-1032

8. Schryvers D, Ma Y (1995) In situ TEM study of the $\mathrm{Ni}_{5} \mathrm{Al}_{3}$ to $\mathrm{B} 2+\mathrm{L}_{2}$ decomposition in $\mathrm{Ni}_{65} \mathrm{Al}_{35}$. Mater Lett 23:105-111

9. Otsuka K, Ren X (2005) Physical metallurgy of Ti-Ni-based shape memory alloys. Prog Mater Sci 50:511-678

10. Bataillard L, Bidaux J-E, Gotthardt R (1998) Interaction between microstructure and multiple-step transformation in binary $\mathrm{NiTi}$ alloys using in situ transmission electron microscopy observations. Philos Mag A 78:327-344

11. Frenzel J, George EP, Dlouhy A, Somsen C, Wagner M-X, Eggeler G (2010) Influence of $\mathrm{Ni}$ on martensitic phase transformations in niti shape memory alloys. Acta Mater 58:3444-3458

12. Tang W (1997) Thermodynamic study of the low-temperature phase B19 and the martensitic transformation in near-equiatomic Ti-Ni shape memory alloys. Metall Mater Trans A 28:537-544

13. Tirry W, Schryvers D, Jorissen K, Lamoen D (2006) Electrondiffraction structure refinement of $\mathrm{Ni}_{4} \mathrm{Ti}_{3}$ precipitates in $\mathrm{Ni}_{52} \mathrm{Ti}_{48}$. Acta Crystallogr B 62:966-971

14. Jansen J, Tang D, Zandbergen HW, Schenk H (1998) MSLS, a least-squares procedure for accurate crystal structure refinement from dynamical electron diffraction patterns. Acta Crystallogr A 54:91-101

15. Jansen J, Zandbergen HW (2002) Determination of absolute configurations of crystal structures using electron diffraction patterns by means of least-squares refinement. Ultramicroscopy 90:291-300

16. Michutta J, Somsen C, Yawny A, Dlouhy A, Eggeler G (2006) Elementary martensitic transformation processes in Ni-rich $\mathrm{NiTi}$ single crystals with $\mathrm{Ni}_{4} \mathrm{Ti}_{3}$ precipitates. Acta Mater 54:3525-3542

17. Tirry W, Schryvers D (2005) Quantitative determination of strain fields around $\mathrm{Ni}_{4} \mathrm{Ti}_{3}$ precipitates in NiTi. Acta Mater 53:1041-1049

18. Tirry W, Schryvers D (2009) Linking a completely three-dimensional nanostrain to a structural transformation eigenstrain. Nat Mater 8:752-757

19. Hÿtch MJ, Snoeck E, Kilaas R (1998) Quantitative measurement of displacement and strain fields from HREM micrographs. Ultramicroscopy 74:131-146

20. Yang Z, Tirry W, Schryvers D (2005) Analytical TEM investigations on concentration gradients surrounding $\mathrm{Ni}_{4} \mathrm{Ti}_{3}$ precipitates in Ni-Ti shape memory material. Scr Mater 52:1129-1134
21. Wang X, Kustov S, Li K, Schryvers D, Verlinden B, Van Humbeeck J (2015) Effect of nanoprecipitates on the transformation behavior and functional properties of a Ti-50.8 at.\% Ni alloy with micron-sized grains. Acta Mater 82:224-233

22. Yang Z, Tirry W, Lamoen D, Kulkova S, Schryvers D (2008) Electron energy-loss spectroscopy and first-principles calculation studies on a Ni-Ti shape memory alloy. Acta Mater 56:395-404

23. Khalil-Allafi J, Dlouhy J, Eggeler G (2002) $\mathrm{Ni}_{4} \mathrm{Ti}_{3}$-precipitation during aging of NiTi shape memory alloys and its influence on martensitic phase transformations. Acta Mater 50:4255-4274

24. Khalil-Allafi J, Ren X, Eggeler G (2002) The mechanism of multistage martensitic transformations in aged Ni-rich NiTi shape memory alloys. Acta Mater 50:793-803

25. Dlouhy A, Khalil-Allafi J, Eggeler G (2003) Multiple-step martensitic transformations in Ni-rich NiTi alloys-an in situ transmission electron microscopy investigation. Phil Mag 83:339-363

26. Nishida M, Hara T, Ohba T, Yamaguchi K, Tanaka K, Yamauchi K (2003) Experimental consideration of multistage martensitic transformation and precipitation behavior in aged Ni-rich Ti-Ni shape memory alloys. Mater Trans 44:2631-2636

27. Cao S, Nishida M, Schryvers D (2011) Quantitative three-dimensional analysis of $\mathrm{Ni}_{4} \mathrm{Ti}_{3}$ precipitate morphology and distribution in polycrystalline Ni-Ti. Acta Mater 59:1780-1789

28. Cao S, Pourbabak S, Schryvers D (2012) Quantitative 3-D morphologic and distributional study of $\mathrm{Ni}_{4} \mathrm{Ti}_{3}$ precipitates in a $\mathrm{Ni}_{51} \mathrm{Ti}_{49}$ single crystal alloy. Scr Mater 66:650-653

29. Cao S, Somsen C, Croitoru M, Schryvers D, Eggeler G (2010) Focused ion beam/scanning electron microscopy tomography and conventional transmission electron microscopy assessment of $\mathrm{Ni}_{4} \mathrm{Ti}_{3}$ morphology in compression-aged Ni-rich $\mathrm{Ni}-\mathrm{Ti}$ single crystals. Scr Mater 62:399-402

30. Yao X, Cao S, Zhang XP, Schryvers D (2015) Microstructural characterization and transformation behavior of porous $\mathrm{Ni}_{50.8-}$ $\mathrm{Ti}_{49.2}$. Materials Today. In: Proceedings of international conference on martensitic transformations ICOMAT-2014 (to be published)

31. Cui J, Chu YS, Famodu OO, Furuya Y, Hattrick-Simpers J, James RD et al (2006) Combinatorial search of thermoelastic shapememory alloys with extremely small hysteresis width. Nat Mater 5:286-290

32. Delville R, Schryvers D (2010) Transmission electron microscopy study of combined precipitation of $\mathrm{Ti}_{2} \mathrm{Ni}(\mathrm{Pd})$ and $\mathrm{Ti}_{2}$ $\mathrm{Pd}(\mathrm{Ni})$ in a $\mathrm{Ti}_{50} \mathrm{Ni}_{30} \mathrm{Pd}_{20}$ alloy. Intermetallics 18:2353-2360

33. Wang M, Jiang M, Liao G, Guo S, Zhao X (2012) Martensitic transformation involved mechanical behaviors and wide hysteresis of NiTiNb shape memory alloys. Prog Nat Sci 22:130-138

34. Zhao LC, Duerig TW, Justi S, Melton KN, Proft JL, Yu W, Wayman CM (1990) The study of Niobium-rich precipitates in a Ni-Ti-Nb shape memory alloy. Scr Metall Mater 24:221-225

35. Shi H, Frenzel J, Martinez GT, Van Rompaey S, Bakulin A, Kulkova $\mathrm{S}$ et al (2014) Site occupation of $\mathrm{Nb}$ atoms in ternary NiTi-Nb shape memory alloys. Acta Mater 74:85-95

36. Shi H, Pourbabak S, Van Humbeeck J, Schryvers D (2012) Electron microscopy study of Nb-rich nanoprecipitates in Ni-Ti$\mathrm{Nb}$ and their influence on the martensitic transformation. Scr Mater 67:939-942 